\title{
Planos nutricionais de lisina digestível para suínos machos imunocastrados em crescimento e terminação
}

\author{
Charles Kiefer ${ }^{1}$, Juarez Lopes Donzele ${ }^{2}$, Rita Flávia Miranda de Oliveira ${ }^{2}$
}

\begin{abstract}
${ }^{1}$ DZO/FAMEZ/UFMS.
2 DZO/CCA/UFV.
\end{abstract}

RESUMO - Conduziu-se este estudo com o objetivo de avaliar planos nutricionais de lisina digestível para suínos machos na fase dos 67 aos 165 dias de idade imunocastrados aos 107 e aos 135 dias. Foram utilizados 240 animais com peso inicial de $27,73 \pm 1,57 \mathrm{~kg}$ distribuídos em delineamento de blocos ao acaso, com quatro planos nutricionais de lisina digestível para suínos imunocastrados (0,9-0,8-0,7; 1,0-0,9-0,8; 1,1-1,0-0,9 e 1,2-1,1-1,0\%, respectivamente, dos 67 aos 107 dias, dos 108 aos 135 dias e dos 136 aos 165 dias), com quatro repetições e um plano controle para suínos castrados (1,1-1,0-0,9\% de lisina digestível), com oito repetições de dez animais. O plano nutricional com a sequência de 1,1-1,0-0,9\% de lisina digestível melhorou a conversão alimentar, reduziu a espessura de toucinho e aumentou a quantidade de carne magra na carcaça dos suínos em comparação aos demais planos nutricionais. As demais variáveis de desempenho e características de carcaça não foram influenciadas pelos planos nutricionais. Planos nutricionais com fornecimento de lisina digestível na sequência de 1,1-1,0-0,9\%, respectivamente, para os períodos de 67 aos 107 dias, dos 108 aos 135 dias e dos 136 aos 165 dias, atendem às necessidades nutricionais de suínos machos imunocastrados aos 107 e aos 135 dias de idade.

Palavras-chave: aminoácidos, desempenho, exigências nutricionais, proteína ideal

\section{Nutritional plans of digestible lysine for growing-finishing imunocastrated boars}

\begin{abstract}
This study was conducted to evaluate nutritional plans of digestible lysine for boars 67 to 165 days of age, immunocastrated at their 107 and 135 days. Two hundred and forty animals, with initial body weight of $27.73 \pm 1.57 \mathrm{~kg}$, were sorted in a randomized block design with four nutritional plans of digestible lysine for immunocastrated pigs (0.9-0.8-0.7; 1.0-0.9-0.8; 1.1-1.0-0.9 and 1.2-1.1-1.0\%, respectively from 67 to 107 days, from 108 to 135 days and 136 to 165 days) with four replications and a control plan for barrows (1.1-1.0-0.9\% of digestible lysine) with eight replications and ten animals each. The nutritional plan with the sequence containing 1.1-1.0-0.9\% digestible lysine improved feed conversion, reduced backfat thickness and increased the amount of lean meat of pigs carcass when compared to other nutritional plans. The other performance and carcass variables were not affected by nutritional plans. Nutritional plans with the sequence 1.1-1.0-0.9\% of digestible lysine for periods of 67 to 107 days, 108 to 135 days and 136 to 165 days, respectively, meet the nutritional needs of immunocastrade boars 107 to 135 days old.
\end{abstract}

Key Words: amino acids, ideal protein, growth performance, nutritional requirements

\section{Introdução}

$\mathrm{Na}$ suinocultura mundial, os suínos machos destinados ao abate são, em grande parte, submetidos a castração cirúrgica (gonadectomia) com a finalidade de eliminar o odor sexual na carne (Babol et al., 1998), causado pelo acúmulo ou associação da androsterona e escatol (Zamaratskaia et al., 2008a). Considerando apenas países da União Europeia, estima-se que cerca de 100 milhões de leitões sejam castrados anualmente (Thun et al., 2006).
Sabe-se, porém, que suínos machos castrados apresentam mais baixa eficiência alimentar e retenção de nitrogênio, além de menor relação carne:gordura, o que torna sua produção significativamente mais onerosa quando comparada à produção de suínos machos não-castrados (Xue et al., 1997).

Nesse sentido, a imunocastração tem sido uma alternativa cada vez mais utilizada na produção de suínos em substituição ao método tradicional de castração cirúrgica dos machos. O princípio da imunocastração baseia-se na aplicação de vacinas contendo uma forma modificada de 
GnRH (hormônio liberador de gonadotrofinas) conjugada a uma proteína que induz a formação de anticorpos direcionados contra o GnRH (Zamaratskaia et al., 2008b). A supressão do GnRH impede o estímulo à secreção de LH e FSH pela glândula pituitária, reduzindo o desenvolvimento dos testículos e a síntese de hormônios esteroides (Bauer et al., 2008; Pauly et al., 2009), incluindo a androsterona (Zamaratskaia et al., 2008b), principal responsável pelo odor na carcaça.

Por sua vez, a imunocastração permite aos machos nãocastrados a produção de hormônios anabolizantes andrógenos até a aplicação da segunda dose da vacina (Zamaratskaia et al., 2008b), fato que possibilita a manutenção da superioridade do desempenho e deposição de carne magra na carcaça (Jaros et al., 2005). Todavia, suínos machos imunocastrados possivelmente apresentam metabolismo diferenciado em relação aos machos castrados e às fêmeas, fato que pode ocasionar mudanças também de suas exigências nutricionais, principalmente de proteína.

Considerando a carência de informações sobre estratégias de nutrição proteica destinada a suínos imunocastrados, realizou-se este estudo com o objetivo de avaliar planos nutricionais para suínos machos não-castrados de alto potencial genético na fase dos 67 aos 165 dias de idade imunocastrados aos 107 e aos 135 dias.

\section{Material e Métodos}

O experimento foi realizado na suinocultura Rancho Alegre, localizada no município de Campo Grande, Mato Grosso do Sul. Foram utilizados 240 suínos, sendo 160 machos imunocastrados e 80 machos castrados, Duroc/ Pietran $\times$ Large White/Landrace, de alto potencial genético para deposição de proteína na carcaça, com 67 dias de idade e peso inicial de $27,73 \pm 1,57 \mathrm{~kg}$.

Os animais foram distribuídos em delineamento de blocos ao acaso, com quatro planos nutricionais de lisina digestível para machos imunocastrados $(0,9-0,8-0,7$; 1,0-0,9-0,8; 1,1-1,0-0,9 e 1,2-1,1-1,0\%, respectivamente, nas fases dos 67 aos 107 dias, dos 108 aos 135 dias e dos 136 aos 165 dias) e um plano nutricional para machos castrados (constituído pelos níveis de 1,1-1,0-0,9\% de lisina digestível para as mesmas fases), com quatro repetições por plano nutricional, no caso dos machos imunocastrados, e oito repetições para os machos castrados, com dez animais por baia, considerada a unidade experimental. Na formação dos blocos, levou-se em consideração o peso inicial dos animais.

As dietas experimentais para as fases dos 67 aos 107 dias (Tabela 1), 108 aos 135 dias (Tabela 2) e 136 aos 165 dias
Tabela 1 - Composição das dietas experimentais dos 67 aos 107 dias de idade

\begin{tabular}{|c|c|c|c|c|}
\hline \multirow[t]{2}{*}{ Ingrediente } & \multicolumn{4}{|c|}{ Lisina digestível (\%) } \\
\hline & 0,90 & 1,00 & 1,10 & 1,20 \\
\hline Milho grão & 64,287 & 64,287 & 64,287 & 64,287 \\
\hline Farelo de soja $45 \%$ & 30,745 & 30,745 & 30,745 & 30,745 \\
\hline Fosfato bicálcico & 1,207 & 1,207 & 1,207 & 1,207 \\
\hline Banha & 1,425 & 1,425 & 1,425 & 1,425 \\
\hline Inerte (caulim) & 1,000 & 0,826 & 0,568 & 0,301 \\
\hline Calcário & 0,631 & 0,631 & 0,631 & 0,631 \\
\hline Sal comum & 0,405 & 0,405 & 0,405 & 0,405 \\
\hline Suplemento vitamínico ${ }^{1}$ & 0,150 & 0,150 & 0,150 & 0,150 \\
\hline Suplemento mineral ${ }^{2}$ & 0,150 & 0,150 & 0,150 & 0,150 \\
\hline L-lisina $\mathrm{HCl}$ & 0,000 & 0,129 & 0,258 & 0,387 \\
\hline DL-metionina & 0,000 & 0,039 & 0,099 & 0,160 \\
\hline L-treonina & 0,000 & 0,006 & 0,075 & 0,144 \\
\hline L-triptofano & 0,000 & 0,000 & 0,000 & 0,008 \\
\hline \multicolumn{5}{|c|}{ Composição nutricional calculada ${ }^{3}$} \\
\hline $\begin{array}{l}\text { Energia metabolizável } \\
(\mathrm{kcal} / \mathrm{kg})\end{array}$ & 3.230 & 3.230 & 3.230 & 3.230 \\
\hline Proteína bruta (\%) & 19,24 & 19,24 & 19,24 & 19,24 \\
\hline Lisina digestível (\%) & 0,900 & 1,000 & 1,100 & 1,200 \\
\hline Triptofano digestível (\%) & 0,208 & 0,208 & 0,208 & 0,216 \\
\hline Treonina digestível (\%) & 0,644 & 0,650 & 0,715 & 0,780 \\
\hline $\begin{array}{l}\text { Metionina + cistina } \\
\text { digestível (\%) }\end{array}$ & 0,562 & 0,600 & 0,660 & 0,720 \\
\hline Isoleucina digestível (\%) & 0,739 & 0,739 & 0,739 & 0,739 \\
\hline Valina digestível (\%) & 0,815 & 0,815 & 0,815 & 0,828 \\
\hline Cálcio (\%) & 0,631 & 0,631 & 0,631 & 0,631 \\
\hline Fósforo disponível (\%) & 0,330 & 0,330 & 0,330 & 0,330 \\
\hline Fósforo total (\%) & 0,541 & 0,541 & 0,541 & 0,541 \\
\hline Sódio (\%) & 0,180 & 0,180 & 0,180 & 0,180 \\
\hline
\end{tabular}

${ }^{1}$ Conteúdo por quilograma de produto: ferro - $100 \mathrm{~g}$; cobre - $10 \mathrm{~g}$; cobalto - $1,0 \mathrm{~g}$ manganês - 40 g; zinco - 100 g; iodo - 1,5 g; selênio - 0,3 g; excipiente q.s.p. $1.000 \mathrm{~g}$

${ }^{2}$ Conteúdo por quilograma de produto: vit. A - 6.000.000 UI; vit. $\mathrm{D}_{3}-1.500 .000$ UI; vit. E - 15.000 UI; vit. $B_{1}-1,35$ g; vit. $B_{2}-4,0$ g; vit. $B_{6}-2,0$ g; ácido pantotênico - 10 g; vit. $K_{3}-1,5$ g; ácido nicotínico - 22 g; vit. $B_{12}-0,2$ g; ácido fólico - 0,6 g; biotina - 0,08 g; colina - $100 \mathrm{~g}$; excipiente q.s.p. - $1.000 \mathrm{~g}$.

${ }^{3}$ Valores calculados com base na composição nutricional das matérias primas (Rostagno et al., 2005).

(Tabela 3) foram compostas principalmente de milho e farelo de soja, suplementadas com minerais e vitaminas para atender às exigências nutricionais dos animais (Rostagno et al., 2005) em todos os nutrientes, exceto lisina.

Os níveis de lisina digestível das dietas experimentais foram obtidos a partir da inclusão de L-lisina $\mathrm{HCl}$ em substituição ao caulim. As relações aminoacídicas entre lisina e os demais aminoácidos essenciais foram atendidas de acordo com o padrão de proteína ideal estabelecido por Rostagno et al. (2005). As rações e a água foram fornecidas à vontade aos animais durante todo o período experimental. Os resíduos de ração do chão foram coletados diariamente, pesados e somados às sobras do comedouro no final do experimento.

Os animais foram alojados em baias equipadas com comedouros automáticos e bebedouros do tipo chupeta localizadas em prédio de alvenaria, com piso de concreto e coberto com telha de cerâmica. As variações térmicas no 
Tabela 2 - Composição das dietas experimentais dos 108 aos 135 dias de idade

\begin{tabular}{|c|c|c|c|c|}
\hline \multirow[t]{2}{*}{ Ingrediente } & \multicolumn{4}{|c|}{ Lisina digestível (\%) } \\
\hline & 0,80 & 0,90 & 1,00 & 1,10 \\
\hline Milho grão & 69,304 & 69,304 & 69,304 & 69,30 \\
\hline Farelo de soja $45 \%$ & 26,416 & 26,416 & 26,416 & 26,41 \\
\hline Fosfato bicálcico & 0.968 & 0.968 & 0.968 & 0.968 \\
\hline Banha & 1,034 & 1,034 & 1,034 & 1,034 \\
\hline Inerte (caulim) & 1,000 & 0,827 & 0,562 & 0,280 \\
\hline Calcário & 0,598 & 0,598 & 0,598 & 0,598 \\
\hline Sal comum & 0,380 & 0,380 & 0,380 & 0,380 \\
\hline Suplemento vitamínico ${ }^{1}$ & 0,150 & 0,150 & 0,150 & 0,150 \\
\hline Suplemento mineral ${ }^{2}$ & 0,150 & 0,150 & 0,150 & 0,150 \\
\hline L-lisina $\mathrm{HCl}$ & 0,000 & 0,129 & 0,258 & 0,387 \\
\hline DL- & 0,000 & 0, & 0, & 0,156 \\
\hline L-t & 0 & 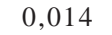 & & 0,155 \\
\hline L-triptofano & 0,000 & 0,000 & 0,003 & 0,022 \\
\hline \multicolumn{5}{|c|}{ Composição nutricional calculada ${ }^{3}$} \\
\hline $\begin{array}{l}\text { Energia metabolizável } \\
\text { (kcal/kg) }\end{array}$ & 3.230 & 3.230 & 3.230 & 3.230 \\
\hline Proteína bruta (\%) & 17,69 & 17,69 & 17,69 & 17,69 \\
\hline Lisina digestível (\%) & 0,800 & 0,900 & 1,0 & 1,100 \\
\hline Triptofano digestível (\%) & 0,187 & 0,187 & 0,190 & 0,209 \\
\hline Treonina digestível (\%) & 0,590 & 0,603 & 0,67 & 0,737 \\
\hline $\begin{array}{l}\text { Metionina + cistina } \\
\text { digestível (\%) }\end{array}$ & 0,528 & 0,558 & 0,620 & 0,682 \\
\hline a digestível (\%) & 0,670 & 70 & 0,6 & 0,670 \\
\hline Valina digestível (\%) & 0,750 & 0,750 & 0,7 & 0,759 \\
\hline Cálcio (\%) & 0,551 & 0,551 & 0,551 & 0,551 \\
\hline Fósforo disponível (\%) & 0,282 & 0,282 & 0,282 & 0,282 \\
\hline Fósforo total (\%) & 0,485 & 0,485 & 0,485 & 0,485 \\
\hline Sódio (\%) & 0,170 & 0,170 & 0,170 & 0,170 \\
\hline \multicolumn{5}{|c|}{$\begin{array}{l}{ }^{1} \text { Conteúdo por quilograma de produto: ferro - } 100 \text { g; cobre - } 10 \text { g; cobre - 0,2 g; } \\
\text { manganês - } 30 \text { g; zinco - } 100 \text { g; iodo - } 1,0 \text { g; selênio - 0,3 g; excipiente q.s.p. - } \\
1.000 \text { g. } \\
{ }^{2} \text { Conteúdo por quilograma de produto: vit. A - } 6.000 .000 \text { UI; vit. D3 - } 1.000 .000 \\
\text { UI; vit. E - } 12.000 \text { UI; vit. B1 - 0,5 g; vit. B2 - 2,6 g; vit. B6 - 0,7 g; ácido } \\
\text { pantotênico - } 10 \text { g; vit. K3 - } 1,5 \text { g; ácido nicotínico - } 22 \text { g; vit. B12 - 0,015 g; } \\
\text { ácido fólico - 0,2 g; biotina - 0,05 g; colina - } 100 \text { g e excipiente q.s.p. - } 1.000 \text { g. } \\
3 \text { Valores calculados com base na composição nutricional das matérias primas } \\
\text { (Rostagno et al., 2005). }\end{array}$} \\
\hline
\end{tabular}

interior do galpão foram monitoradas diariamente às 7, 12 e $17 \mathrm{~h}$, por meio de um conjunto de termômetros de bulbo seco, bulbo úmido e de globo negro instalados no centro do galpão. Os valores registrados foram convertidos no índice de temperatura de globo e umidade para caracterizar o ambiente térmico em que os animais foram mantidos.

No início (67 dias de idade) e ao final do experimento (165 dias de idade), os animais foram pesados para determinação do consumo de ração, do ganho de peso e da conversão alimentar. Os suínos machos foram imunocastrados por meio da aplicação de vacina específica à base de análogo sintético incompleto do GnRF conjugado a uma proteína carreadora. Foram realizadas duas aplicações subcutâneas, de $2 \mathrm{~mL}$ cada uma: a primeira aos 107 dias e a segunda aos 135 dias de idade.

Ao término do experimento, os animais foram submetidos a jejum de sólidos de 24 horas, embarcados em caminhão e transportados para o abatedouro. No
Tabela 3 - Composição das dietas experimentais dos 136 aos 165 dias de idade

\begin{tabular}{|c|c|c|c|c|}
\hline \multirow[t]{2}{*}{ Ingrediente } & \multicolumn{4}{|c|}{ Lisina digestível (\%) } \\
\hline & 0,70 & 0,80 & 0,90 & 1,00 \\
\hline Milho grão & 73,706 & 73,706 & 73,706 & 73,706 \\
\hline Farelo de soja $45 \%$ & 22,133 & 22,133 & 22,133 & 22,133 \\
\hline Fosfato bicálcico & 0,990 & 0,990 & 0,990 & 0,990 \\
\hline Banha & 0,883 & 0,883 & 0,883 & 0,883 \\
\hline Inerte (caulim) & 1,000 & 0,866 & 0,599 & 0,317 \\
\hline Calcário & 0,607 & 0,607 & 0,607 & 0,607 \\
\hline Sal comum & 0,380 & 0,380 & 0,380 & 0,380 \\
\hline Suplemento vitamínico ${ }^{1}$ & 0,150 & 0,150 & 0,150 & 0,150 \\
\hline Suplemento mineral $^{2}$ & 0,150 & 0,150 & 0,150 & 0,150 \\
\hline L-lisina $\mathrm{HCl}$ & 0,000 & 0,129 & 0,258 & 0,387 \\
\hline DL-metionina & 0,000 & 0,003 & 0,066 & 0,129 \\
\hline L-treonina & 0,000 & 0,002 & 0,072 & 0,143 \\
\hline L-triptofano & 0,000 & 0,000 & 0,005 & 0,024 \\
\hline L-isoleucina & 0,000 & 0,000 & 0,000 & 0,000 \\
\hline \multicolumn{5}{|c|}{ Composição nutricional calculada ${ }^{3}$} \\
\hline $\begin{array}{l}\text { Energia metabolizável } \\
\text { (kcal/kg) }\end{array}$ & 3.230 & 3.230 & 3.230 & 3.230 \\
\hline Proteína bruta (\%) & 16,11 & 17,69 & 17,69 & 17,69 \\
\hline Lisina digestível (\%) & 0,700 & 0,800 & 0,900 & 1,000 \\
\hline Triptofano digestível (\%) & 0,166 & 0,166 & 0,171 & 0,190 \\
\hline Treonina digestível (\%) & 0,535 & 0,536 & 0,603 & 0,670 \\
\hline $\begin{array}{l}\text { Metionina + cistina } \\
\text { digestível (\%) }\end{array}$ & 0,493 & 0,496 & 0,558 & 0,620 \\
\hline Isoleucina digestível (\%) & 0,600 & 0,600 & 0,600 & 0,600 \\
\hline Valina digestível (\%) & 0,683 & 0,683 & 0,683 & 0,690 \\
\hline Cálcio (\%) & 0,551 & 0,551 & 0,551 & 0,551 \\
\hline Fósforo disponível (\%) & 0,282 & 0,282 & 0,282 & 0,282 \\
\hline Fósforo total (\%) & 0,485 & 0,485 & 0,485 & 0,485 \\
\hline Sódio (\%) & 0,170 & 0,170 & 0,170 & 0,170 \\
\hline
\end{tabular}

${ }^{1}$ Conteúdo por quilograma de produto: ferro - $100 \mathrm{~g}$; cobre - $10 \mathrm{~g}$; cobalto - 0,2 g; manganês - 30 g; zinco - 100 g; iodo - 1,0 g; selênio - 0,3 g; excipiente q.s.p. - 1.000 g. ${ }^{2}$ Conteúdo por quilograma de produto: vit. A - 6.000.000 UI; vit. D3 - 1.000 .000 UI; vit. E - 12.000 UI; vit. B1 - 0,5 g; vit. B2 - 2,6 g; vit. B6 - 0,7 g; ácido pantotênico - 10 g; vit. K3 - 1,5 g; ácido nicotínico - 22 g; vit. B12 - 0,015 g; ácido fólico - 0,2 g; biotina - 0,05 g; colina - 100 g e excipiente q.s.p. - 1.000 g.

3 Valores calculados com base na composição nutricional das matérias-primas (Rostagno et al., 2005).

abatedouro, foram alojados em baias coletivas de espera com acesso à vontade à água. Por ocasião do abate, os suínos foram pesados, insensibilizados por eletronarcose e, posteriormente, sangrados, escaldados e eviscerados.

Ao final da linha de abate, foi realizado um corte na meia-carcaça esquerda, na região de inserção da última vértebra torácica com a primeira lombar a $6 \mathrm{~cm}$ da linha média de corte da carcaça (ponto $\mathrm{P}_{2}$ ), onde foram determinadas a espessura de toucinho, a profundidade de músculo e a área de olho-de-lombo. A porcentagem de carne magra na carcaça foi determinada por meio de equação utilizando-se os valores de espessura de toucinho e profundidade de músculo. O rendimento de carcaça foi calculado com base no peso de abatedouro e no peso de carcaça quente.

As variáveis de desempenho avaliadas foram consumo de ração, ganho de peso e conversão alimentar e as características quantitativas de carcaça foram peso, rendimento de carcaça, espessura de toucinho, profundidade 
de músculo, percentual de carne magra e quantidade de carne magra na carcaça.

Os dados obtidos foram submetidos à análise de variância pelo procedimento anova do programa estatístico SAS (2001). As eventuais diferenças das variáveis obtidas entre os planos nutricionais foram avaliadas pelo teste Tukey a $10 \%$ de significância. As médias obtidas para os suínos machos castrados foram comparadas às dos machos imunocastrados por meio de análise de contrastes.

\section{Resultados e Discussão}

Durante o período experimental, os valores médios de temperatura do ar, umidade relativa do ar, temperatura de globo negro e índice de temperatura de globo e umidade corresponderam a $28,5 \pm 2,6^{\circ} \mathrm{C}, 88,3 \pm 10,4 \%, 28,6 \pm 2,6^{\circ} \mathrm{C}$ e $79,2 \pm 3,1$, respectivamente. Considerando que a temperatura média registrada durante o período experimental foi superior à crítica máxima de $27^{\circ} \mathrm{C}$ (Sampaio et al., 2004) e que o índice de temperatura de globo e umidade calculado foi similar ao obtido por Orlando et al. (2007) para suínos submetidos a temperaturas ambientais elevadas, pode-se inferir que os animais foram mantidos em ambiente de estresse por calor durante o experimento.

Os planos nutricionais não influenciaram $(\mathrm{P}>0,10)$ o consumo de ração diário dos suínos machos imunocastrados (Tabela 4). Da mesma forma, Gomes et al. (2000) não observaram efeito de níveis de lisina digestível sobre o consumo de ração em suínos machos castrados dos 30 aos $100 \mathrm{~kg}$. Kill et al. (2003) e Fortes (2009), em estudos posteriores, também não constataram efeito de planos nutricionais com níveis de lisina digestível sobre o consumo de ração, respectivamente, em leitoas dos 65 aos 105 kg e machos castrados dos 24 aos $126 \mathrm{~kg}$.

Comparando o desempenho de suínos machos imunocastrados aos castrados (Tabela 4), constatou-se que os imunocastrados mantidos com os planos nutricionais baseados nas sequências de 1,0-0,9-0,8; 1,1-1,0-0,9 e 1,2-1,1-1,0\% de lisina digestível apresentaram menor $(\mathrm{P}<0,06)$ consumo de ração diário em comparação aos machos castrados. Esse fato confirma resultado de estudos como os de Xue et al. (1995), Dunshea et al. (2001), Pauly et al. (2008) e Pauly et al. (2009), que observaram em suínos machos não-castrados menor consumo de ração diário em relação a machos castrados.

Considerando que os suínos imunocastrados permaneceram grande parte do estudo com tecido testicular funcional (Zamaratskaia et al., 2008b), a diferença no consumo observada entre castrados e imunocastrados pode estar relacionada ao nível plasmático de testosterona, que pode inibir o apetite e o consumo de alimento (Campbell \& Taverner, 1988). Essa hipótese pode ser apoiada em estudos de Weiler et al. (1996), que verificaram que a produção de testosterona e o consumo de ração estão negativamente correlacionados em suínos machos não-castrados.

Os planos nutricionais não influenciaram $(\mathrm{P}>0,10)$ o ganho de peso diário dos suínos imunocastrados (Tabela 4). Resultados semelhantes foram obtidos por Gomes et al. (2000), Kill et al. (2003) e Fortes (2009), que não observaram efeito dos planos nutricionais sobre o ganho de peso dos suínos. Também não foram observadas diferenças $(\mathrm{P}>0,10)$ no ganho de peso diário dos machos imunocastrados em relação ao dos castrados. Embora não tenha ocorrido variação significativa entre as duas categorias, os imunocastrados obtiveram consistentemente maiores valores absolutos para o ganho em relação aos castrados.

No caso específico deste estudo, as altas temperaturas ambientais ocorridas durante o período experimental podem justificar o fato de a taxa de crescimento dos animais não ter variado entre os planos nutricionais. Confirmando essa proposição, o ganho de peso médio de 936 g/dia observado

Tabela 4 - Desempenho de suínos machos imunocastrados e castrados em função dos planos nutricionais

\begin{tabular}{|c|c|c|c|c|c|c|c|}
\hline Categoria & & $\begin{array}{c}\text { Plano } \\
\text { nutricional }\end{array}$ & $\begin{array}{c}\text { Peso } \\
\text { inicial (kg) }\end{array}$ & $\begin{array}{l}\text { Peso } \\
\text { final (kg) }\end{array}$ & $\begin{array}{l}\text { Consumo de } \\
\text { ração diário (g) }\end{array}$ & $\begin{array}{c}\text { Ganho de } \\
\text { peso diário (g) }\end{array}$ & $\begin{array}{l}\text { Conversão } \\
\text { alimentar* }\end{array}$ \\
\hline Machos imunocastrados & 1 & $-0,9-0,8-0,7$ & 27,90 & 118,58 & 2.355 & 936 & $2,52 \mathrm{a}$ \\
\hline Machos imunocastrados & 2 & $-1,0-0,9-0,8$ & 27,91 & 118,17 & 2.311 & 931 & $2,48 \mathrm{a}$ \\
\hline Machos imunocastrados & 3 & $-1,1-1,0-0,9$ & 27,47 & 119,93 & 2.233 & 954 & $2,34 b$ \\
\hline Machos imunocastrados & 4 & - 1,2-1,1-1,0 & 27,69 & 117,12 & 2.253 & 923 & $2,44 \mathrm{a}$ \\
\hline Machos castrados & 5 & $-1,1-1,0-0,9$ & 27,19 & 113,70 & 2.351 & 893 & 2,63 \\
\hline \multicolumn{8}{|c|}{ Probabilidade de $\mathrm{F}$ para os contrastes } \\
\hline Imunocastrados $\times$ castrados & & $1 \times 5$ & 0,841 & $0,065 * *$ & 0,116 & 0,741 & $0,001 * *$ \\
\hline Imunocastrados $\times$ castrados & & $2 \times 5$ & 0,828 & $0,043 * *$ & $0,038 * *$ & 0,858 & $0,001 * *$ \\
\hline Imunocastrados $\times$ castrados & & $3 \times 5$ & 0,735 & $0,024 * *$ & $0,001 * *$ & 0,370 & $0,001 * *$ \\
\hline Imunocastrados $\times$ castrados & & $4 \times 5$ & 0,407 & $0,066 * *$ & $0,053 * *$ & 0,132 & $0,001 * *$ \\
\hline CV (\%) & & - & 3,59 & 3,56 & 4,64 & 5,23 & 2,53 \\
\hline
\end{tabular}

*Médias dos machos imunocastrados seguidas por letras distintas diferem $(\mathrm{P}<0,10)$ pelo teste Tukey.

** Média dos machos imunocastrados diferem $(\mathrm{P}<0,10)$ da média dos machos castrados pelo teste de contrastes. 
nos suínos imunocastrados neste estudo ficou abaixo daquele de $1.040 \mathrm{~g} /$ dia proposto por Rostagno et al. (2005) para suínos machos castrados na mesma faixa de peso e com potencial genético similar.

Os planos nutricionais influenciaram $(\mathrm{P}<0,05)$ a conversão alimentar dos machos imunocastrados em que os animais alimentados com a dieta correspondente à sequência de 1,1-1,0-0,9\% de lisina digestível apresentaram melhor resultado se comparados aos demais planos nutricionais. A melhora na eficiência de utilização do alimento nos animais submetidos aos níveis sequenciais de 1,1-1,0-0,9\% de lisina digestível pode ser um indicativo de que ocorreu variação na composição do ganho, com aumento na deposição de proteína e redução na de gordura. Esta proposição também pode ser justificada pelo fato de que a deposição de tecido proteico, por agregar maior quantidade de água $(1: 3,4)$ em relação à deposição de lipídios na carcaça (Halas et al., 2010), melhora a eficiência de utilização do alimento para ganho de peso dos suínos.

A conversão alimentar dos suínos imunocastrados submetidos aos planos nutricionais foi melhor $(\mathrm{P}<0,01)$ que a dos machos castrados (Tabela 4). Considerando o relato anterior, pode-se deduzir que houve maior deposição diária de proteína na carcaça dos imunocastrados em relação aos castrados. Melhor eficiência de utilização dos nutrientes da dieta para ganho de peso de suínos imunocastrados em comparação aos castrados também foi observada por Dunshea et al. (2001).

O peso final dos suínos machos imunocastrados não foi influenciado $(\mathrm{P}>0,10)$ pelos planos nutricionais (Tabela 4), contudo, os suínos imunocastrados apresentaram maior $(P<0,07)$ peso final em relação aos castrados em todos os planos nutricionais avaliados.

Os planos nutricionais não influenciaram $(\mathrm{P}>0,05) \mathrm{o}$ peso e o rendimento de carcaça quente dos suínos machos imunocastrados (Tabela 5). Por outro lado, os suínos imunocastrados, em todos os níveis nutricionais, apresentaram maior $(\mathrm{P}<0,07)$ peso de carcaça quente em comparação aos castrados. Esse resultado pode ser justificado pelo maior peso corporal final dos machos imunocastrados nos diferentes planos nutricionais. Embora tenham apresentado maior peso de carcaça, os machos imunocastrados que receberam os planos nutricionais correspondentes às sequências de 0,9-0,8-0,7 e 1,0-0,9-0,8\% de lisina digestível tiveram menor $(\mathrm{P}<0,05)$ rendimento de carcaça em comparação aos castrados.

Não houve efeito $(\mathrm{P}>0,10)$ dos planos nutricionais sobre a profundidade de músculo e o percentual de carne magra dos suínos machos imunocastrados nem variação $(\mathrm{P}>0,10)$ nos valores obtidos para essas características entre as categorias avaliadas. Constatou-se efeito $(\mathrm{P}<0,05)$ dos planos nutricionais sobre a espessura de toucinho e a quantidade de carne magra na carcaça dos machos imunocastrados (Tabela 5), uma vez que o plano correspondente à sequência de $1,1-1,0-0,9 \%$ de lisina digestível proporcionou menor espessura de toucinho e maior quantidade de carne magra em relação aos demais planos nutricionais.

O aumento da quantidade de carne magra na carcaça, associado à redução da espessura de toucinho, está coerente com a resposta obtida para eficiência alimentar dos machos imunocastrados submetidos ao plano nutricional correspondente à sequência de $1,1-1,0-0,9 \%$ de lisina digestível. De forma consistente com essa observação, o estudo realizado por Latorre et al. (2008) confirmou correlação positiva entre deposição de proteína na carcaça e conversão alimentar, indicando que suínos com elevado ganho diário de tecido proteico apresentaram melhor eficiência alimentar.

Não se observou variação $(P>0,10)$ na espessura de toucinho entre os suínos imunocastrados e os castrados (Tabela 5), embora os imunocastrados, exceto aqueles

Tabela 5 - Características de carcaça de suínos machos imunocastrados e castrados em função dos planos nutricionais

\begin{tabular}{|c|c|c|c|c|c|c|c|c|}
\hline Categoria & & $\begin{array}{c}\text { Plano } \\
\text { nutricional }\end{array}$ & $\begin{array}{c}\text { Peso de } \\
\text { carcaça }(\mathrm{kg})\end{array}$ & $\begin{array}{c}\text { Rendimento } \\
\text { de carcaça (\%) }\end{array}$ & $\begin{array}{c}\text { Profundidade } \\
\text { de músculo }(\mathrm{mm})\end{array}$ & $\begin{array}{c}\text { Carne } \\
\text { magra (\%) }\end{array}$ & $\begin{array}{c}\text { Carne } \\
\text { magra }(\mathrm{kg})^{*}\end{array}$ & $\begin{array}{c}\text { Espessura de } \\
\text { toucinho }(\mathrm{mm})^{*}\end{array}$ \\
\hline Machos imunocastrados & 1 & - 0,9-0,8-0,7 & 92,29 & 82,63 & 69,25 & 60,18 & $56,7 b$ & $11,63 a$ \\
\hline Machos imunocastrados & 2 & $-1,0-0,9-0,8$ & 92,55 & 82,68 & 69,13 & 61,40 & $55,6 b$ & $9,50 \mathrm{a}$ \\
\hline Machos imunocastrados & 3 & $-1,1-1,0-0,9$ & 94,71 & 83,42 & 66,88 & 61,83 & $57,2 \mathrm{a}$ & $8,38 b$ \\
\hline Machos imunocastrados & 4 & - 1,2-1,1-1,0 & 93,28 & 83,02 & 66,19 & 61,07 & $56,9 b$ & $9,56 a$ \\
\hline Machos castrados & 5 & - 1,1-1,0-0,9 & 89,52 & 84,36 & 67,00 & 60,36 & 53,9 & 10,93 \\
\hline \multicolumn{9}{|c|}{ Probabilidade de $\mathrm{F}$ para os contrastes } \\
\hline Imunocastrados $\times$ castrados & & $1 \times 5$ & $0,069 * *$ & $0,036 * *$ & 0,389 & 0,355 & $0,060 * *$ & 0,118 \\
\hline Imunocastrados $\times$ castrados & & $2 \times 5$ & $0,055 * *$ & $0,041 * *$ & 0,408 & 0,515 & $0,025 * *$ & 0,733 \\
\hline Imunocastrados $\times$ castrados & & $3 \times 5$ & $0,027 * *$ & 0,189 & 0,835 & 0,232 & $0,014 * *$ & 0,179 \\
\hline Imunocastrados $\times$ castrados & & $4 \times 5$ & $0,029 * *$ & 0,128 & 0,748 & 0,314 & $0,024 * *$ & 0,297 \\
\hline CV (\%) & & - & 6,78 & 2,90 & 11,50 & 2,60 & 7,07 & 25,67 \\
\hline
\end{tabular}

*Médias dos machos imunocastrados seguidas por letras distintas diferem $(\mathrm{P}<0,10)$ pelo teste Tukey.

** Média dos machos imunocastrados diferem $(\mathrm{P}<0,10)$ da média dos machos castrados pelo teste de contrastes. 
mantidos com o plano nutricional com 0,9-0,8-0,7\% de lisina digestível, tenham apresentado valores absolutos de espessura de toucinho de 12,5 a 23,3\% menores em relação aos castrados. Contudo, os imunocastrados apresentaram maior $(\mathrm{P}<0,07)$ quantidade de carne magra na carcaça em todos os planos nutricionais se comparados aos machos castrados, resultado que pode ser explicado pelo maior peso de carcaça quente dos suínos imunocastrados. Por sua vez, com base em revisão bibliográfica, Xue et al. (1997) observaram superioridade absoluta de machos castrados para área de olho-de-lombo e espessura de toucinho, evidenciando que esses animais apresentam maior capacidade diária de deposição de proteína na carcaça em relação aos castrados.

A partir dos resultados obtidos, pode-se inferir que suínos machos imunocastrados apresentam desempenho e características de carcaça superiores em comparação aos castrados, o que implica aumento da exigência em aminoácidos na dieta. Os resultados obtidos para conversão alimentar, espessura de toucinho e quantidade de carne magra indicam que o plano nutricional correspondente à sequência de 1,1-1,0-0,9\% de lisina digestível é o mais adequado para suínos machos imunocastrados dos 67 aos 165 dias de idade.

\section{Conclusões}

Planos nutricionais com fornecimento de lisina digestível na sequência de 1,1-1,0-0,9\%, respectivamente, dos 67 aos 107 dias, dos 108 aos 135 dias e dos 136 aos 165 dias atendem às necessidades nutricionais de suínos machos imunocastrados aos 107 e aos 135 dias de idade.

\section{Referências}

BABOL, J.; SQUIRES, E.J.; LUNDISTROM, K. Hepatic metabolism of skatole in pigs by cytochrome P4502E1. Journal of Animal Science, v.76, p.822-828, 1998.

BAUER, A.; LACORN, M.; DANOWSKI, K. et al. Effects of immunization against GnRH on gonadotropins, the GH-IGF-Iaxis and metabolic parameters in barrows. Animal, v.2, p.12151222, 2008

CAMPBELL, R.G.; TAVERNER, M.R. Genotype and sex effects on the relationship between energy intake and protein deposition in growing pigs. Journal of Animal Science, v.66, p.676-686, 1988.

DUNSHEA, F.R.; COLANTONI, C.; HOWARD, K. et al. Vaccination of boars with a GnRH vaccine (Improvac) eliminates boar taint and increases growth performance. Journal of Animal Science, v.79, p.2524-2535, 2001.

FORTES, E.I. Níveis de lisina digestível e planos de nutrição para suínos machos castrados de duas linhagens genéticas. 2009. 46f. Dissertação (Mestrado em Zootecnia). Universidade Federal de Viçosa, Viçosa, MG.
GOMES, F.E.; FIALHO, E.T.; LIMA, J.A.F. et al. Planos de nutrição baseados em níveis de lisina para suínos de diferentes genótipos abatidos aos 80 e 100 kg de peso vivo. Ciência Agrotécnica, v.24, p.479-489, 2000.

HALAS, V.C.; BABINSZKY, L.; DIJKSTRA, J. et al. Efficiency of fat deposition from non-starch polysaccharides, starch and unsaturated fat in pigs. British Journal of Nutrition, v.103, p.123-133, 2010.

JAROS, P.; BÜRGI, E.; STÄRK, K.D.C. et al. Effect of active immunization against $\mathrm{GnRH}$ on androstenone concentration, growth performance and carcass quality in intact male pigs. Livestock Production Science, v.92, p.31-38, 2005.

KILL, J.L.; DONZELE, J.L.; OLIVEIRA, R.F.M. et al. Planos de nutrição para leitoas com alto potencial genético para deposição de carne magra dos 65 aos $105 \mathrm{~kg}$. Revista Brasileira de Zootecnia, v.32, p.1330-1338, 2003

LATORRE, M.A.; POMAR, C.; FAUCINTANO, L. et al. The relationship within and between production performance and meat quality characteristics in pigs form three different genetic lines. Livestock Science, v.115, p.258-267, 2008.

ORLANDO, U.A.D.; OLIVEIRA, R.F.M.; DONZELE, J.L. et al Níveis de proteína bruta e suplementação de aminoácidos em dietas para leitoas mantidas em ambiente de alta temperatura dos 60 aos $100 \mathrm{~kg}$. Revista Brasileira de Zootecnia, v.36, p.1069-1075, 2007.

PAULY, C.; SPRING, P.; O’DOHERTY, J.V. et al. Growth performance, carcass characteristics and meat quality of grouppenned surgically castrated immunocastrated (Improvac ${ }^{\circledR}$ ) and entire male pigs and individually penned entire male pigs. Animal, v.3, p.1057-1066, 2009.

PAULY, C.; SPRING, P.; O’DOHERTY, J.V. et al. Performances, meat quality and boar taint of castrates and entire male pigs fed a standard and a raw potato starch-enriched diet. Animal, v.2, p.1707-1715, 2008.

ROSTAGNO, H.S.; ALBINO, L.F.T.; DONZELE, J.L. et al. Tabelas brasileiras para aves e suínos: composição de alimentos e exigências nutricionais. 2.ed. Viçosa, MG: UFV, 2005. 186p.

SAMPAIO, C.A.P.; CRISTANI, J.; DUBIELA, J.A. et al. Avaliação do ambiente térmico em instalações para crescimento e terminação de suínos utilizando os índices de conforto térmico nas condições tropicais. Ciência Rural, v.34, p.785-790, 2004.

STATISTICAL ANALYSIS SYSTEM - SAS. SAS user's guide: statistic, version 8.2, 6.ed. Cary: 2001. Todd and Browde.

THUN, R.; GAJEWSKI, Z.; JANETT, F.F. Castration in male pigs: techniques and animal welfare issues. Journal of Physiology and Pharmacology, v.57, p.189-194, 2006.

XUE, J.L.; DIAL, G.D.; PETTIGREW, J.E. Performance, carcass, and meat quality advantages of boars over barrow: a literature review. Swine Health and Production, v.5, p.21-28, 1997.

XUE, J.L.; DIAL, G.D.; SCHUITEMAN, J. et al. Evaluation of growth, carcass, and compound concentrations related to boar taint in boars and barrows. Swine Health and Production, v.3, p.155-160, 1995.

WEILER, U.; CLAUS, R.; DEHNHARD, M. et al. Influence of the photoperiod and a light reverse program on metabolically active hormones and food intake in domestic pigs compared with a wild boar. Canadian Journal of Animal Science, v.76, p.531-539, 1996.

ZAMARATSKAIA, G.; ANDERSSON, H.K.; CHEN, G. et al. Effect of a gonadotropin-releasing hormone vaccine (Improvac ${ }^{\mathrm{TM}}$ ) on steroid hormones, boar taint compounds and performance in entire male pigs. Reproduction in Domestic Animals, v.43, p.351-359, 2008a.

ZAMARATSKAIA, G.; RYDHMER, L.; ANDERSSON, H.K. et al. Long-term effect of vaccination against gonadotropinreleasing hormone, using Improvac ${ }^{\mathrm{TM}}$, on hormonal profile and behaviour of male pigs. Animal Reproduction Science, v.108, p.37-48, 2008b. 